\title{
Innate immune responses of whiteleg shrimp (Penaeus vannamei) experimentally infected with acute hepatopancreas necrosis disease-causing Vibbrio parahaemolyticus
}

\author{
Tuan V. Vo*, Truc T. T. Nguyen, \& Binh T. T. Vo
}

Faculty of Fisheries, Nong Lam University, Ho Chi Minh City, Vietnam

\begin{abstract}
ARTICLE INFO
Research Paper

Received: March 22, 2018

Revised: August 29, 2018

Accepted: September 18, 2018

Keywords

Immune responses

Penaeus vannamei

Vibrio parahaemolyticus

${ }^{*}$ Corresponding author

Vo Van Tuan

Email: vovantuan@hcmuaf.edu.vn
\end{abstract}

\section{ABSTRACT}

The innate immune responses of the whiteleg shrimps (Penaeus vannamei) experimentally challenged with $V$. parahaemolyticus by immersion were investigated for a period of $120 \mathrm{~h}$. The results showed that the lethal dose $50 \%\left(\mathrm{LD}_{50}\right)$ of shrimps $(2-3 \mathrm{~g})$ challenged with $V$. parahaemolyticus was $4.7 \times 106 \mathrm{CFU} / \mathrm{mL}$. No significant differences in immune parameters were observed between the control and challenged group right after challenge $(0 \mathrm{hpi})$. However, the total haemocyte count, phenoloxidase activity and respiratory burstsactivity were decreased in the challenged shrimps after 24 and $48 \mathrm{hpi}$ and significantly different from those in the control shrimps $(P<0,05)$. At 72,96 and $120 \mathrm{hpi}$, there were no significant differences in the total haemocyte count, phenoloxidase activity and respiratory burst activity between two treatments. The observations of this study showed that the innate immune responses of the whiteleg shrimp were decreased due to the infection by V. parahaemolyticus.

Cited as: Vo, T. V., Nguyen, T. T. T., \& Vo, B. T. T. (2019). Innate immune responses of whiteleg shrimp (Penaeus vannamei) experimentally infected with acute hepatopancreas necrosis diseasecausing Vibbrio parahaemolyticus. The Journal of Agriculture and Development 18(1), 80-88. 


\title{
Đáp ứng miễn dịch tự nhiên của tôm thẻ chân trắng, Penaeus vannamei, cảm nhiễm bởi vi khuẩn gây hoại tử gan tụy cấp Vibbrio parahaemolyticus
}

\author{
Võ Văn Tuấn*, Nguyễn Thị Thanh Trúc \& Võ Thị Thanh Bình \\ Khoa Thủy Sản, Trường Đại Học Nông Lâm TP. Hồ Chí Minh, TP. Hồ Chí Minh
}

\section{THÔNG TIN BÀI BÁO}

Bài báo khoa học

Ngày nhận: 22/03/2018

Ngày chỉnh sửa: 29/08/2018

Ngày chấp nhận: 18/09/2018

\section{Từ khóa}

Đáp ứng miễn dịch

Penaeus vannamei

Vibrio parahaemolyticus

*Tác giả liên hệ

Võ Văn Tuấn

Email: vovantuan@hcmuaf.edu.vn

\section{TÓM TẮT}

Nghiên cứu đáp ứng miễn dịch tự nhiên của tôm thẻ chân trắng $(P e-$ naeus vannamei) cảm nhiễm bởi vi khuẩn $V$. parahaemolyticus thông qua phương pháp ngâm được thực hiện trong điều kiện phòng thí nghiệm trong thời gian 120 giờ. Kết quả thí nghiệm cho thấy chủng vi khuẩn $V$. parahaemolyticus sử dụng gây cảm nhiễm trên tôm thẻ $(2-3 \mathrm{~g})$ với liều gây chết $50 \%\left(\mathrm{LD}_{50}\right)$ là $4,7 \times 106 \mathrm{CFU} / \mathrm{mL}$. Không có sự khác biệt về các chỉ tiêu miễn dịch giữa nghiệm thức đối chứng và nghiệm thức gây nhiễm ở thời điểm $0 \mathrm{~h}$. Tuy nhiên, ở thời điểm 24 và $48 \mathrm{~h}$, tổng tế bào máu, hoạt tính phenoloxidase và hoạt tính của gốc oxy hoá tự do (respiratory burst) ở tôm cảm nhiễm bởi $\mathrm{V}$. parahaemolyticus giảm đáng kể và khác biệt có ý nghĩa so với nhóm đối chứng $(P<0,05)$. Ở các thời điểm thu mẫu tiếp theo $(72,96$ và 120 giờ) thì không có sự khác biệt về tổng tế bào máu, hoạt tính phenoloxidase và hoạt tính của gốc oxy hoá tự do giữa hai nghiệm thức. Từ kết quả này có thể kết luận rằng hệ thống miễn dịch tự nhiên của tôm thẻ bị suy yếu do cảm nhiễm vi khuẩn gây bệnh hoại tử gan tuỵ cấp V. parahaemolyticus.

\section{1. Đặt Vấn Đề}

Tôm thẻ, Penaeus vannamei, là một trong những loài tôm được nuôi khá phổ biến ở vùng Western (Menz \& Blake, 1980) và chiếm khoảng $95 \%$ tổng sản lượng tôm nuôi (Lightner, 2011). Với việc gia tăng diện tích nuôi và thâm canh hóa dẫn đến sự xuất hiện và lây lan của nhiều tác nhân gây bệnh nguy hiểm (Lightner, 2011), đặc biệt là bệnh do vi khuẩn và virus. Những năm gần đây, ngành nuôi tôm trên thế giới nói chung và Việt Nam nói riêng đang phải đối mặt với một dịch bệnh mới với tên gọi ban đầu là hội chứng chết sớm (early mortality syndrome - EMS) hay bệnh hoại tử gan tụy cấp tính (Acute hepatopancreas necrosis syndrome - APHND) trên tôm thẻ chân trắng. Khả năng bệnh bùng phát và lây lan rất nhanh. Bệnh xuất hiện đầu tiên tại Trung Quốc (2009), sau đó lây lan nhanh sang Việt Nam (2010), Malaysia (2011), Thái Lan (2012), Mexico (2014), và Philippines (2015) (Zorriehzahra \& Banaederakhshan, 2015).
Hệ thống miễn dịch của giáp xác nói chung và của tôm nói riêng thiếu những yếu tố cần thiết cho đáp ứng miễn dịch đặc hiệu như tế bào lympho T, phân tử MHC (major histocompatability) và $\mathrm{Ig}$. Quá trình đề kháng ở giáp xác chủ yếu dựa vào cơ chế đáp ứng miễn dịch không đặc hiệu (miễn dịch tự nhiên), trong đó tế bào máu giữ vai trò quan trọng trong quá trình đáp ứng miễn dịch ở giáp xác nhằm chống lại các tác nhân gây bệnh như vi khuẩn, nấm, ký sinh trùng... (Bachere \& ctv., 2004; Jose \& ctv., 2010; Matozzo \& Marin, 2010). Té bào máu ở giáp xác tham gia trực tiếp vào quá trình nhận diện, thực bào, phong toả và sản sinh ra các hợp chất kháng khuẩn như phenoloxidase, các gốc oxy hoá tự do (reactive oxygen intermediates), superoxide dismutase (Song \& Hsieh, 1994; Herández-López \& ctv., 1996; Dantas-Lima \& ctv., 2013). Quá trình thực bào ở giáp xác, đặc biệt là tôm thẻ $(P e$ naeus vannamei) đối với tác nhân vi khuẩn gây bệnh như Vibrio harveyi, Vibrio campbellii đã được nghiên cứu bởi tác giả (Vo \& ctv., 2015). 
Phương pháp phân tích các chỉ tiêu miễn dịch đã được nghiên cứu trên tôm càng xanh (Macrobrachium rosenbergii) (Dang \& ctv., 2012). Các nghiên cứu về quá trình đáp ứng miễn dịch tự nhiên của tôm thẻ cảm nhiễm bởi vi khuẩn $V i b$ rio alginolyticus đã được ghi nhận (Liu \& ctv., 2004; Tseng \& Chen, 2004; Hsu \& Chen, 2007). Tuy nhiên, có rất ít nghiên cứu về khả năng đáp ứng miễn dịch tự nhiên của tôm thẻ sau khi bị cảm nhiễm bởi tác nhân vi khuẩn gây bệnh hoại tử gan tụy cấp tính (Vibrio parahaemolyticus). Do đó, mục tiêu của đề tài nhằm đánh giá khả năng đáp ứng miễn dịch tự nhiên của tôm thẻ cảm nhiễm bởi vi khuẩn gây bệnh hoại tử gan tụy cấp.

\section{Vật Liệu và Phương Pháp Nghiên Cứu}

\subsection{Vật liệu nghiên cứu}

Tôm thẻ $\left(\mathrm{PL}_{11}\right)$, nhập từ Trại sản xuất tôm giống sạch bệnh của công ty Việt Úc, được nuôi trong hệ thống tuần hoàn tại Trại thực nghiệm Thuỷ sản - Khoa Thuỷ sản, Trường Đại học Nông Lâm TP.HCM. Tôm được cho ăn 2 lần/ngày với $5 \%$ trọng lượng thân. Nhiệt độ nước trong bể được duy trì ở mức $27 \pm 1^{0} \mathrm{C}, \mathrm{pH} 7,5-8,0$, độ mặn $12 \pm 1 \mathrm{~g} / \mathrm{L}$, độ kiềm > $80 \mathrm{mg} / \mathrm{L}$, ammonia tổng $<0,5 \mathrm{mg} / \mathrm{L}$, và nitrite $<0,15 \mathrm{mg} / \mathrm{L}$. Tôm với trọng lượng từ $2-3 \mathrm{~g}$ sẽ được chọn để tiến hành thí nghiệm.

Vi khuẩn Vibrio parahaemolyticus gây bệnh hoại tử gan tuỵ cấp (EMS/APHND) được phân lập, định danh và giữ giống $\left(-80^{\circ} \mathrm{C}\right)$ tại phòng thí nghiệm Bệnh học Thuỷ sản, Khoa Thuỷ sản, trường Đại học Nông Lâm TP.HCM.

\subsection{Phương pháp nghiên cứu}

\subsubsection{Vi khuẩn và điều kiện nuôi cấy}

Vi khuẩn Vibrio parahaemolyticus được phục hồi trên môi trường TCBS (Thiosulfate Citrate Bile Salt), bổ sung $1 \% \mathrm{NaCl}$, ở nhiệt độ $28^{\circ} \mathrm{C}$ trong 24 giờ. Chọn một khuẩn lạc cấy thuần sang môi trường TSA (Tryptic Soya Agar), bổ sung $1 \% \mathrm{NaCl}$, ở nhiệt độ $28^{0} \mathrm{C}$ trong 24 giờ. Sau đó chọn một khuẩn lạc riêng lẻ tăng sinh trong môi trường TSB (Tryptic Soya Broth), bổ sung 1\% $\mathrm{NaCl}$, ở nhiệt độ $30^{\circ} \mathrm{C}$ trong 7 giờ với số vòng lắc 150 vòng/phút. Mật độ vi khuẩn sẽ được xác định bằng máy đo quang phổ ở bước sóng 610 nm, sau đó sẽ được quy đổi dựa trên công thức đường chuẩn $\mathrm{CFU} / \mathrm{mL}=\left(11,92 \times \mathrm{OD}_{610 \mathrm{~nm}}-\right.$ $1,13) \times 10^{8}$ (số liệu chưa công bố).

\subsubsection{Phương pháp xác định $\mathrm{LD}_{50}$ (Lethal Dose $50 \%$ ) của chủng vi khuẩn $V$. parahaemolyti- cus}

Thí nghiệm xác định giá trị $\mathrm{LD}_{50}$ được bố trí theo phương pháp hoàn toàn ngẫu nhiên với bốn nghiệm thức có các liều gây nhiễm chênh lệch nhau 10 lần và một nghiệm thức đối chứng không gây nhiễm. Vi khuẩn sau khi tăng sinh trong môi trường TSB, bổ sung $1 \% \mathrm{NaCl}$, ở nhiệt độ $30^{\circ} \mathrm{C}$ trong 7 giờ với số vòng lắc 150 vòng/phút. Sau đó tiến hành gây bệnh thực nghiệm bằng cách cho trực tiếp huyền phù vi khuẩn vào bể thí nghiệm $50 \mathrm{~L}$ (chứa $18 \mathrm{~L}$ nước và $2 \mathrm{~L}$ canh vi khuẩn) để đạt được nồng độ pha loãng $10^{-1}$. Sau đó, lây 2 $\mathrm{L}$ nước từ bể này cho vào bể thứ hai chứa $18 \mathrm{~L}$ nước để đạt nồng độ pha loãng $10^{-2}$. Tiếp tục làm như vậy cho cho bể thứ ba và thứ tư để đạt nồng độ pha loãng là $10^{-3}$ và $10^{-4}$. Tôm được ngâm 2 giờ, sau đó rửa qua nước biển với độ mặn $12 \pm 1 \mathrm{~g} / \mathrm{L}$ và sẽ được bố trí vào bể thí nghiệm mới chứa $20 \mathrm{~L}$ nước. Mỗi bể được bố trí 20 tôm (2-3 g/con) tương ứng với một nồng độ pha loãng và được lặp lại 3 lần. Tôm ở bể đối chứng được ngâm trong $20 \mathrm{~L}$ nước với lượng TSB bằng với lượng TSB chứa huyền phù vi khuẩn trong bể thí nghiệm. Thí nghiệm được theo dõi trong 10 ngày. Tôm có biệu hiện bệnh lý sẽ được thu mẫu (gan tụy) cấy phân lập trên môi trường TCBS và môi trường chọn lọc Chromagar Vibrio. Giá trị $\mathrm{LD}_{50}$ được tính theo công thức (Reed \& Muench, 1938):

$$
\begin{aligned}
& \log \mathrm{LD}_{50}=\log (\text { tỷ lệ chết }>50 \%)+\left(\log \left(10^{-1}\right)\right. \\
& \times \mathrm{pd})=\mathrm{y} . \\
& \mathrm{pd}=((\text { tỷ lệ chết }>50 \%)-50) /((\text { tỷ lệ chết }> \\
& 50 \%)-(\text { tỷ lệ chết }<50 \%)) . \\
& \mathrm{LD}_{50}=10^{\mathrm{y}} \text {. }
\end{aligned}
$$

Liều gây chết $50 \%=$ (nồng độ vi khuẩn trong huyền phù ban đầu) $\times 10^{\mathrm{y}}$.

\subsubsection{Thí nghiệm xác định các chỉ tiêu miễn dịch trên tôm}

Thí nghiệm xác định các chỉ tiêu miễn dịch được bố trí ngẫu nhiên trong hệ thống bể composit $50 \mathrm{~L}$ (chứa $20 \mathrm{~L}$ nước), sục khí liên tục. Nhiệt độ nước dao động từ $27 \pm 1^{0} \mathrm{C}, \mathrm{pH} 7,5-$ 8,0, độ mặn $12 \pm 1 \mathrm{~g} / \mathrm{L}$, độ kiềm > $80 \mathrm{mg} / \mathrm{l}$, ammonia tổng $<0,5 \mathrm{mg} / \mathrm{l}$, và nitrite $<0,15 \mathrm{mg} / \mathrm{L}$. Tôm thẻ $2-3 \mathrm{~g}$ được bố trí vào bể với số lượng 
10 con/ bể/ thời điểm thu mẫu và được lặp lại 3 lần. Tôm sau khi được bố trí vào bể tiếp tục được thuần dưỡng 2 ngày. Tôm sẽ được gây bệnh thông qua phương pháp ngâm (dựa vào kêt quả LD50 của chủng vi khuẩn $V$. parahaemolyticus). Tôm ở nghiệm thức đối chứng được ngâm trong 20 L nước với lượng TSB (Trytic Soya Broth) bằng với lượng TSB chứa huyền phù vi khuẩn trong bể thí nghiệm. Sau khi gây cảm nhiễm, mẫu tôm sẽ được thu vào các thời điểm như $0,24,48,72,96$ và 120 giờ để lấy máu xác định các chỉ tiêu miễn dịch. Mỗi bể thu ngẫu nhiên 3 con.

\subsubsection{Phương pháp phân lập và định danh vi khuẩn}

Vi khuẩn từ mẫu tôm bệnh sẽ được tái phân lập trên môi trường TCBS và Chromagar Vibrio (bổ sung $1 \% \mathrm{NaCl}$ ). Thu mẫu tôm bệnh, tách phần gan tuỵ tôm và nghiền trong dung dịch đệm sPBS (shrimp phosphate buffer saline). Hút 0,1 $\mathrm{mL}$ dịch nghiền cho vào môi trường TCBS $(1 \%$ $\mathrm{NaCl}$ ), tran đều và ủ 24 giờ ở $30^{\circ} \mathrm{C}$. Chọn khuẩn lạc riêng lẻ cấy thuần trên môi trường TCBS, TSA và Chromagar Vibrio $(1 \% \mathrm{NaCl})$. Quan sát hình dạng, màu sắc khuẩn lạc và tiến hành định danh vi khuẩn bằng IDS 14 GRNS (14 phản ứng sinh hoá dùng để định danh trực khuẩn gram âm) của Công ty Nam Khoa.

\subsubsection{Phương pháp phân tích các chỉ tiêu miễn dịch}

Các chỉ tiêu miễn dịch như tổng tế bào máu, định loại tế bào máu (tế bào không hạt, tế bào bán hạt và tế bào hạt), khả năng tạo ra các hợp chất kháng khuẩn dựa vào tài liệu nghiên cứu của Song \& Hsieh, 1994; Herández-López \& ctv., 1996; Dantas - Lima \& ctv., 2013; Vo \& ctv., 2015.

Tổng tế bào máu: máu tôm được thu bằng cách dùng ống tiêm vô trùng $1 \mathrm{~mL}$ có chứa dung dịch chống đông (marine anticoagulant: $450 \mathrm{mM}$ $\mathrm{NaCl}, 100 \mathrm{mM}$ glucose, $30 \mathrm{mM}$ trisodium citrate, $26 \mathrm{mM}$ citric acid, $10 \mathrm{mM}$ EDTA, $\mathrm{pH} 5,4)$ với tỷ lệ 1:1 (200 $\mu \mathrm{L}$ dung dịch chống đông: $200 \mu \mathrm{L}$ máu tôm). Mật độ tế bào máu được xác định bằng buồng đếm hồng cầu và quan sát dưới kính hiển vi (40X).

Tổng tế bào máu $(\mathrm{tb} / \mathrm{mL})=$ tổng tế bào đếm được trong 4 ô lớn $\times 2500 \times$ hệ số pha loãng (Hansen, 2000).

Định loại tế bào máu: qui trình thực hiện tiêu bản, nhuộm và định loại tế bào được thực hiện theo phương pháp của Dantas-Lima \& ctv. (2013). Máu tôm được thu bằng ống tiêm vô trùng $(1 \mathrm{~mL})$ có chứa dung dịch chống đông, sau đó đem ly tâm với lực ly tâm $500 \mathrm{xg}$ trong 10 phút ở $4^{0} \mathrm{C}$. Phần dịch phía trên được loại bỏ và phần viên được cố định trong dung dịch marine fixative ( $2 \%$ glutaraldehyde $+2 \%$ saccharose) trong 30 phút ở $4^{0} \mathrm{C}$. Mẫu máu được trãi lên lam thủy tinh, làm khô, cố định 5 phút trong ethanol, rửa bằng nước cất và nhuộm với haematoxylin và eosin. Quan sát tiêu bản dưới vật kính hiển vi $(100 \mathrm{X})$ và đếm tổng 200 tế bào (Hrubec \& ctv., 2000).

Định loại tế bào $(\mathrm{tb} / \mathrm{mL})=$ (số lượng mỗi loại tế bào $\times$ tổng tế bào máu) $/ 200$.

\subsubsection{Phương pháp xác định hoạt tính phenoloxi- dase (PO)}

Hoạt tính phenoloxidase được xác định dựa theo phương pháp của Herández-López \& ctv. (1996) với một số hiệu chỉnh. Mẫu máu sau khi thu được ly tâm với lực ly tâm 500 xg trong 10 phút ở $4^{0} \mathrm{C}$, sau đó loại bỏ phần dịch phía trên. Phần viên được hòa tan trong $1 \mathrm{~mL}$ dung dịch đệm cacodylate-citrate $(0,01 \mathrm{M}$ sodium cacodylate, $0,45 \mathrm{M}$ sodium chloride và $0,1 \mathrm{M}$ trisodium citrate, $\mathrm{pH}$ 7,0). Ly tâm một lần nữa ở 500 $\mathrm{xg}$ trong 10 phút ở $4^{0} \mathrm{C}$, loại bỏ phần dịch, phần viên lại được hòa tan với $200 \mu \mathrm{L}$ dung dịch đệm cacodylate $(0,01 \mathrm{M}$ sodium cacodylate, 0,45M sodium chloride, $0,01 \mathrm{M}$ calcium chloride và $0,26 \mathrm{M}$ magnesiumchloride, $\mathrm{pH} 7,0) .100 \mu \mathrm{L}$ mẫu được cho vào đĩa 96 giếng (96-cell culture plates), cho tiếp $50 \mu \mathrm{L}$ trypsin $(1 \mathrm{mg} / \mathrm{mL})$ vào và ủ trong 10 phút ở nhiệt độ phòng. Sau đó, $50 \mu \mathrm{L} \mathrm{L-DOPA}(3 \mathrm{mg} / \mathrm{mL})$ được cho vào và ủ 10 phút. Tiếp theo, cho $800 \mu \mathrm{L}$ dung dịch đệm cacodylate vào. Đọc kết quả bằng máy so màu quang phổ (microplate reader) ở bước sóng 490 nm. Mẫu đối chứng gồm có $100 \mu \mathrm{L}$ mẫu, $50 \mu \mathrm{L}$ đệm cacodylate (thay thế trypsin) và $50 \mu \mathrm{L}$ LDOPA (L-3,4-dihydroxyphenylalanine).

\subsubsection{Phương pháp xác định hoạt tính gốc oxy hoá tự do (respiratory burst)}

Hoạt tính respiratory burst được xác định theo phương pháp của Song \& Hsieh (1994) với một vài hiệu chỉnh. Mẫu máu sau khi thu được ly tâm ở $500 \mathrm{xg}$ trong 10 phút ở $4^{0} \mathrm{C}$, loại bỏ phần dịch phía trên, sau đó phần viên được hòa tan trong 1 $\mathrm{mL}$ môi trường nuôi cấy tế bào (L-15 medium). 
$100 \mu \mathrm{L}$ mẫu máu được cho vào đĩa 96 giếng và được ủ ở nhiệt độ $27-28^{0} \mathrm{C}$ trong 30 phút. Loại bỏ phần dịch, sau đó cho vào $100 \mu \mathrm{L}$ zymosan (0,1\% zymosan trong Hanks' solution minus phenol red, Sigma). Ủ 30 phút ở nhiệt độ $27-28^{\circ} \mathrm{C}$, loại bỏ zymosan, tế bào máu được rửa 3 lần với $100 \mu \mathrm{L}$ dung dịch sPBS (shrimp phosphate buffered saline). Mẫu được nhuộm với $100 \mu \mathrm{L}$ dung dịch nitroblue tetrazolium chloride (NBT) $(0,3 \%)$ trong 30 phút ở nhiệt độ phòng, rồi loại bỏ dung dịch NBT. Tế bào máu sau đó được rửa 3 lần với $100 \mu \mathrm{L}$ methanol $70 \%$, để khô, rồi hòa tan bằng cách thêm vào $120 \mu \mathrm{L} \mathrm{KOH} 2 \mathrm{M}$ và 140 $\mu \mathrm{L}$ dimethyl sulphoxide. Mẫu được đo bằng máy microplate reader ở bước sóng $630 \mathrm{~nm}$.

\subsubsection{Phương pháp phân tích thống kê}

Tất cả các số liệu được xử lý bằng phần mềm Microsoft Excel thông qua trắc nghiệm T-test với mức ý nghĩa $0,05 \%$.

\section{Kết Quả và Thảo Luận}

\subsection{Liều $\mathrm{LD}_{50}$ của chủng vi khuẩn $V$. para- haemolyticus}

Vi khuẩn Vibrio parahaemolyticus là một trong những tác nhân vi khuẩn gây bệnh nguy hiểm đã xuất hiện trong thời gian qua và gây thiệt hại nghiêm trọng cho ngành công nghiệp nuôi tôm toàn cầu (Tran \& ctv., 2013; Lee \& ctv., 2015). Từ kết quả thí nghiệm, chúng tôi nhận thấy rằng, tôm được gây nhiễm bởi chủng vi khuẩn $V$. parahaemolyticus xuất hiện các triệu chứng bệnh như lờ đờ, phản xạ chậm và một vài con có dấu hiệu bỏ ăn sau 1 ngày gây nhiễm. Tôm bắt đầu chết sau 2 ngày gây nhiễm và số lượng tôm chết tăng dần đến ngày thứ 10. Phần gan tuỵ tôm bệnh nhạt màu, mềm và dễ vở khi ấn nhẹ. Kết quả phân lập những con tôm có biểu hiện bệnh cho thấy, vi khuẩn cho khuẩn lạc màu xanh trên môi trường $\mathrm{TCBS}$ và màu tím hoa cà trên môi trường Chromagar Vibrio (Hình 1). Kết quả định danh đã chứng minh được, vi khuẩn có các đặc điểm sinh hoá phù hợp với chủng $V$. parahaemolyticus.

Số lượng và tỷ lệ tôm chết trung bình ở các nghiệm thức trong thí nghiệm xác định liều gây chết $50 \%$ động vật thí nghiệm $\left(\mathrm{LD}_{50}\right)$ được trình bày qua Bảng 1. Kết quả kiểm tra mật độ vi khuẩn bằng máy đo quang phổ ở bước sóng 610 $\mathrm{nm}\left(\mathrm{OD}_{610} \mathrm{~nm}\right)$ và quy đổi dựa trên công thức đường chuẩn $\mathrm{CFU} / \mathrm{mL}=\left(11,92 \times \mathrm{OD}_{610 \mathrm{~nm}}-\right.$

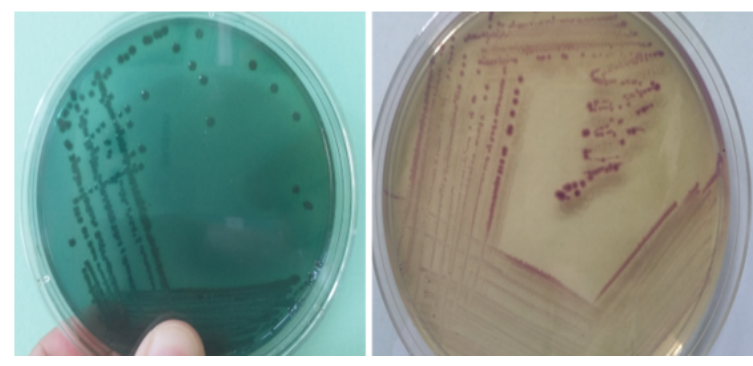

Hình 1. Hình thái khuẩn lạc Vibrio parahaemolyticus trên môi trường TCBS và Chromagar Vibrio.

$1,13) \times 10^{8}$ cho thấy, mật độ vi khuẩn $V$. parahaemolyticus trong bình tăng sinh gốc đạt 7,5 $\times 10^{8} \mathrm{CFU} / \mathrm{ml}$. Như vậy, liều gây nhiễm ở các nghiệm thức NT $10^{-1}$, NT $10^{-2}$, NT $10^{-3}$, NT $10^{-4}$, tương ứng với liều vi khuẩn gây nhiễm lần lượt là $7,5 \times 10^{7} \mathrm{CFU} / \mathrm{mL}, 7,5 \times 10^{6} \mathrm{CFU} / \mathrm{mL}$, $7,5 \times 10^{5} \mathrm{CFU} / \mathrm{mL}, 7,5 \times 10^{4} \mathrm{CFU} / \mathrm{mL}$. Từ kết quả này, chúng tôi tính toán được liều $\mathrm{LD}_{50}$ (theo phương pháp của Reed \& Muench, 1938) của chủng vi khuẩn $V$. parahaemolyticus là $4,7 \times$ $10^{6} \mathrm{CFU} / \mathrm{mL}$.

Các kết quả nghiên cứu trước đây cho thấy rằng, liều $\mathrm{LD}_{50}$ của chủng Vibrio cao hay thấp còn tuỳ thuộc vào chủng vi khuẩn, phương pháp gây nhiễm và kích cỡ tôm. Theo Robertson \& ctv. (1998), liều $\mathrm{LD}_{50}$ của vi khuẩn $\mathrm{V}$. harveyi trên tôm thẻ post-larvae khi gây nhiễm bằng phương pháp ngâm trong 2 giờ là $5,0 \times 106 \mathrm{CFU} / \mathrm{mL}$. Trong khi liều $\mathrm{LD}_{50}$ của vi khuẩn $V$. alginolyticus trên tôm sú post-larvae là $2,5 \times 10^{6} \mathrm{CFU} / \mathrm{mL}$ (Thakur \& ctv., 2003). Nghiên cứu gần đây của Lopez-Leon \& ctv. (2016) cho thấy, liều LD $_{50}$ của chủng vi khuẩn gây bệnh hoại tử gan tụy cấp trên tôm thẻ Penaeus vannamei $(0,1-0,5$ g) bằng phương pháp ngâm (trong 72 giờ) là 6,0 $\times 10^{4} \mathrm{CFU} / \mathrm{mL}$ đến $3,0 \times 10^{5} \mathrm{CFU} / \mathrm{mL}$. Trong thí nghiệm này, tôm với kích cỡ $2-3 \mathrm{~g}$ được gây nhiễm bằng phương pháp ngâm trong 2 giờ với giá trị $\mathrm{LD}_{50}$ đạt $4,7 \times 10^{6} \mathrm{CFU} / \mathrm{mL}$. Kết quả chúng tôi thu được không có sự khác biệt đáng kể so với các nghiên cứu của Robertson \& ctv. (1998) và Thakur \& ctv. (2003), tuy nhiên cao hơn so với kết quả nghiên cứu của Lopez-Leon \& ctv. (2016). Sự khác biệt này có thể là do sự khác biệt về kích cỡ tôm, thời gian gây nhiễm và độc tính của chủng vi khuẩn $V$. parahaemolyticus. Kết quả cho thấy, khả năng đề kháng của tôm nhỏ đối với vi khuẩn $V$. parahaemolyticus kém hơn so với tôm lớn. 
Bảng 1. Số lượng và tỷ lệ tôm chết ở thí nghiệm xác định $L_{50}$

\begin{tabular}{cccccc}
\hline $\begin{array}{c}\text { Nghiệm thức } \\
(\mathrm{NT})\end{array}$ & $\begin{array}{c}\text { Lần } \\
\text { lặp lại }\end{array}$ & Số tôm bố trí/lần lặp lại & $\begin{array}{c}\text { Số tôm chết } \\
\text { cộng dồn }\end{array}$ & $\begin{array}{c}\text { Số tôm sống } \\
\text { cộng dồn }\end{array}$ & $\begin{array}{c}\text { Tỷ lệ chết } \\
\text { cộng dồn }(\%)\end{array}$ \\
\hline NT $10^{-1}$ & 3 & 20 & 35 & 0 & 100,00 \\
NT $10^{-2}$ & 3 & 20 & 15 & 9,3 & 61,64 \\
NT $10^{-3}$ & 3 & 20 & 4,3 & 26,3 & 14,13 \\
NT $10^{-4}$ & 3 & 20 & 1,3 & 45,0 & 2,88 \\
\hline
\end{tabular}

3.2. Đáp ứng miễn dịch tự nhiên của tôm thẻ cảm nhiễm vi khuẩn $\mathrm{V}$. parahaemolyticus

\subsubsection{Tổng tế bào máu và từng loại tế bào}

Kết quả thực hiện tiêu bản máu và nhuộm với hematoxylin và eosin cho thấy, có 3 loại tế bào được ghi nhận: tế bào không hạt (hyaline cells), tế bào bán hạt (semi-granular cells), và tế bào hạt (granular cells). Kết quả này phù hợp với kết quả của các nghiên cứu trước đó về phân loại tế bào máu giáp xác (Söderhäll \& Smith, 1983; van de Braak \& ctv., 1996; Dantas-Lima \& ctv., 2013)(Hình 2).
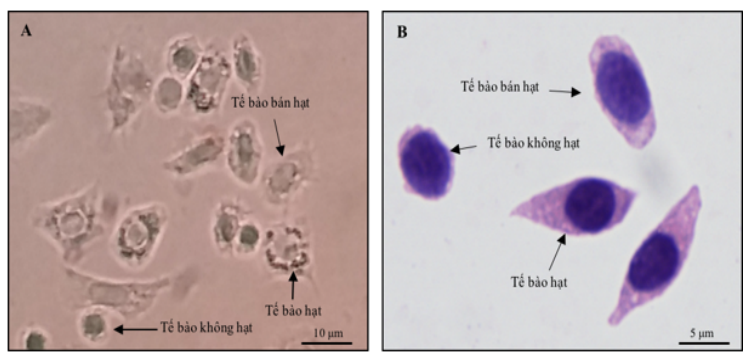

Hình 2. Hình thái tế bào máu tôm thẻ chân trắng ( $\mathrm{A}$ : tế bào được cố định trong dung dịch marine fixative; B: tế bào được nhuộm với hematoxylin và eosin).

Kết quả định lượng cho thấy không có sự khác biệt có ý nghĩa thống kê $(P>0,05)$ về tổng tế bào máu giữa nghiệm thức đối chứng và nghiệm thức gây nhiễm bởi vi khuẩn Vibrio parahaemolyticus ở thời điểm 0 giờ. Tổng tế bào máu ở nghiệm thức đối chứng và nghiệm thức gây nhiễm lần lượt là $43,9 \pm 6,8 \times 10^{5}$ tế bào $/ \mathrm{mL}$ và $41,2 \pm 8,2 \times 10^{5}$ tế bào $/ \mathrm{mL}$. Tổng tế bào máu ở nghiệm thức gây nhiễm giảm $19 \%\left(33,4 \pm 6,1 \times 10^{5}\right.$ tế bào $\left./ \mathrm{mL}\right)$ và $24 \%\left(31,4 \pm 5,9 \times 10^{5}\right.$ tế bào $\left./ \mathrm{mL}\right)$ sau 24 và 48 giờ gây nhiễm với vi khuẩn $V$. parahaemolyticus và khác biệt có ý nghĩa thống kê so với nghiệm thức đối chứng $(P<0,05)$. Ở các thời điểm thu mẫu tiếp theo (72, 96 và 120 giờ) thì không có sự khác biệt có ý nghĩa thống kê về tổng tế bào máu giữa nghiệm thức đối chứng và nghiệm thức gây nhiễm (Bảng 2). Kết quả này tương tự với kết quả nghiên cứu của Hsieh \& ctv. (2008) trên tôm thẻ cảm nhiễm bởi vi khuẩn Vibrio alginolyticus. Kêt quả định loại tế bào cho thấy, không có sự khác biệt có ý nghĩa thống kê về tỷ lệ tế bào không hạt, tế bào bán hạt và tế bào hạt ở nghiệm thức đối chứng và nghiệm thức gây nhiễm ở hầu hết các thời điểm thu mẫu. Tuy nhiên, ở thời điểm 24 giờ, chúng tôi ghi nhận sự khác biệt có ý nghĩa thống kê về tỷ lệ tế bào không hạt, tế bào bán hạt và tế bào hạt giữa nghiệm thức đối chứng và nghiệm thức gây nhiễm $(P<0,05)$. Tế bào không hạt ở nhóm đối chứng chiếm tỷ lệ thấp hơn nhóm gây nhiễm bởi vi khuẩn $V$. parahaemolyticus (đối chứng: $65,6 \%$ và nghiệm thức: $78,9 \%$ ), trong khi tế bào bán hạt và tế bào hạt lại chiếm tỷ lệ cao hơn (tế bào bán hạt ở nhóm đối chứng là $22,2 \%$ và nghiệm thức là $13,3 \%$; tế bào hạt ở nhóm đối chứng là $14,0 \%$ và nghiệm thức là $7,7 \%$ ). Riêng tế bào hạt thì sự khác biệt có ý nghĩa thống kê còn được ghi nhận ở thời điểm 48 giờ (Bảng 2). Tế bào hạt ở nghiệm thức gây nhiễm có khuynh hướng giảm dần nhưng sau đó tăng và ổn định trở lại. Sự biến động này có thể là do cơ chế đáp ứng miễn dịch tự nhiên của giáp xác, và đây cũng là một trong các chỉ tiêu để đánh giá đáp ứng miễn dịch tự nhiên ở tôm. Theo Johansson \& ctv. (2000), tế bào máu của giáp xác giữ vai trò quan trọng trong hệ thống miễn dịch, thực hiện các chức năng như thực bào, đóng gói, lưu trữ và phóng thích prophenoloxidase. Sau khi cảm nhiễm bởi vi khuẩn $V$. parahaemolyticus, hệ miễn dịch của tôm bị suy yếu. Điều đó cũng đồng nghĩa với sự biến động tế bào máu theo chiều hướng giảm, đây cũng là triệu chứng bình thường trong quá trình đáp ứng miễn dịch tự nhiên của giáp xác trong trường hợp nhiễm bệnh. Kết quả nghiên cứu của Hsieh \& ctv. (2008) đã chứng minh rằng, tổng tế bào máu của tôm thẻ giảm đáng kể sau khi bị cảm nhiễm bởi vi khuẩn $\mathrm{V}$. alginolyticus và khác biệt có ý nghĩa thống kê so với nhóm đối chứng. Song \& ctv. (2003) cũng cho thấy rằng, tổng tế bào máu (bao gồm tế bào hạt) giảm đáng kể sau khi 


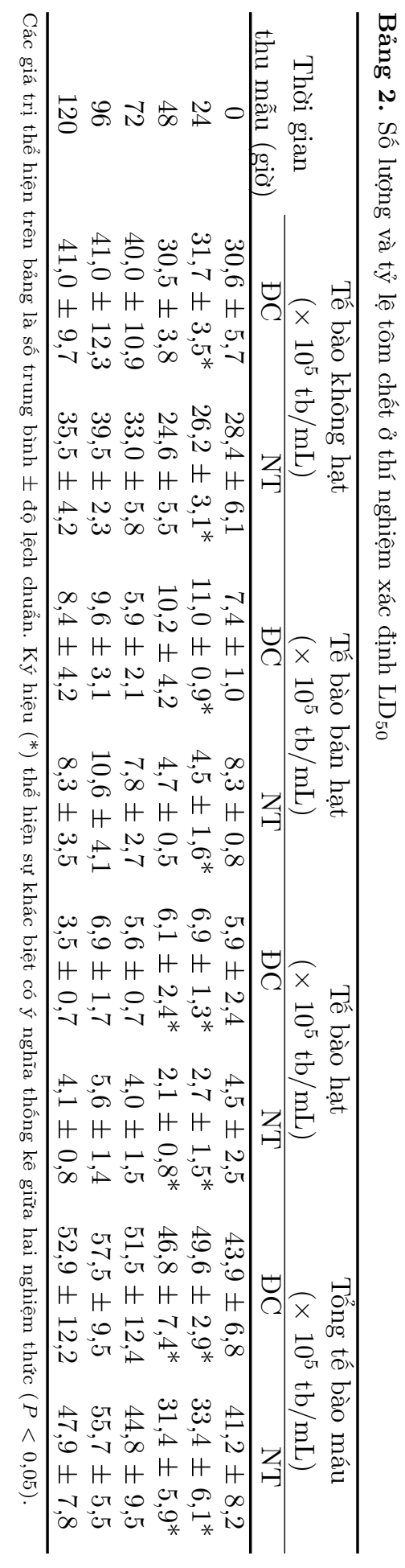

tôm bị nhiễm Taura syndrome virus. Ở các thời điểm thu mẫu như 72,96 và 120 giờ, không có sự khác biệt về tổng tế bào máu và tỷ lệ phần trăm tế bào không hạt, tế bào bán hạt và tế bào hạt giữa hai nghiệm thức. Lý giải cho hiện tượng này có thể là do hệ miễn dịch của tôm đã dần phục hồi trở lại. Kết quả nghiên cứu của chúng tôi cũng gần giống như kết quả nghiên cứu của Hsu \& Chen (2007) trên Penaeus vannamei cảm nhiễm bởi vi khuẩn Vibrio alginolyticus.

\subsubsection{Hoạt tính của Phenoloxidase}

Phenoloxidase là một enzyme quan trọng trong hệ thống miễn dịch tự nhiên của giáp xác. Enzyme này được kích hoạt bởi một lượng nhỏ các thành phần trong vách tế bào vi khuẩn như lipopolysaccharides (LPS) và $\beta-1,3$-glucans từ nấm (Perazzolo \& ctv., 1997; Sritunyalucksana \& ctv., 2000). Khi giáp xác bị mầm bệnh tấn công, enzyme này sẽ được kích hoạt nhằm bất hoạt và ngăn chặn sự lan truyền của tác nhân gây bệnh. Do đó, dựa vào hoạt tính của phenoloxidase, chúng ta có thể đánh giá được quá trình đáp ứng miễn dịch tự nhiên ở giáp xác.

Trong nghiên cứu này, hoạt tính của phenoloxidase ở nghiệm thức gây nhiễm bởi vi khuẩn $V$. parahaemolyticus giảm đáng kể sau 24 và $48 \mathrm{~h}$ gây nhiễm và khác biệt có ý nghĩa thống kê so với nhóm đối chứng $(P<0,05)$, nhưng sau đó ổn định đến hết thời gian thí nghiệm (Hình 3). Nguyên nhân của sự thay đổi này có thể là do hệ thống đáp ứng miễn dịch tự nhiên của tôm bị suy yếu. Theo Wang \& Chen (2005), hoạt tính phenoloxidase ở tôm thẻ sẽ tăng khi có sự tăng lên của tổng tế bào máu, bao gồm tế bào không hạt và tế bào hạt. Kết quả này cũng phù hợp với kết quả nghiên cứu của Hsieh \& ctv. (2008). Ngoài ra, nghiên cứu của Le Moullac \& Haffner (2000) cũng cho thấy rằng, lượng mã hoá enzyme prophenoloxidase giảm đến $60 \%$ khi tôm Litopenaeus stylirostris bị gây stress bởi yếu tố môi trường $\left(\mathrm{NH}_{3}\right)$. Do đó, chúng tôi thiết nghĩ, sự suy giảm hoạt tính phenoloxidase trong nghiên cứu này có thể là kết quả của sự suy giảm lượng mã hoá enzyme prophenoloxidase ở tôm bị nhiễm vi khuẩn $V$. parahaemolyticus.

\subsubsection{Hoạt tính Respiratory burst}

Hoạt tính của gốc oxy hoá tự do (respiratory burst) không có sự khác biệt có ý nghĩa thống kê $(P>0,05)$ giữa nghiệm thức đối chứng và 


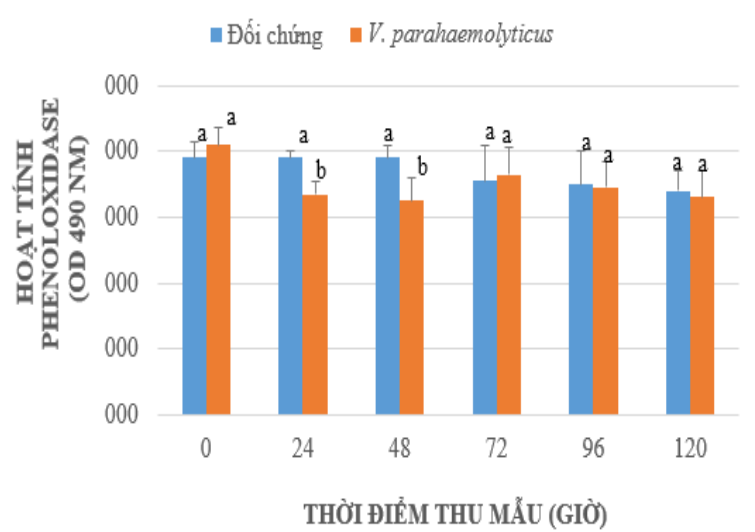

Hình 3. Sự thay đổi hoạt tính phenoloxidase sau khi tôm bị cảm nhiễm bởi vi khuẩn $V$. parahaemolyticus.

nghiệm thức gây nhiễm bởi vi khuẩn Vibrio parahaemolyticus ở thời điểm $0 \mathrm{~h}$. Tuy nhiên, sau 24 và 48 giờ gây nhiễm, hoạt tính respiratory burst giảm đáng kể và khác biệt có ý nghĩa thống kê so với nhóm đối chứng $(P<0,05)$. Ở những thời điểm thu mẫu tiếp theo, không có sự khác biệt về hoạt tính respiratory burst giữa 2 nghiệm thức (Hình 4). Sự khác biệt này có thể là do chức năng miễn dịch tự nhiên của tôm bị suy yếu sau khi tôm bị cảm nhiễm vi khuẩn $V$. parahaemolyticus. Wang \& Chen (2005) đã chứng minh rằng, sự gia tăng hoạt tính respiratory burst là kết quả của sự gia tăng tổng tế bào máu, bao gồm tế bào không hạt và tế bào hạt. Tuy nhiên, hoạt tính của enzyme NADPH-oxidase (giữ vai trò quan trọng trong quá trình giải phóng oxy hoạt hoá superoxide anion) giảm ở tôm bị nhiễm bệnh, kết quả là hoạt tính của respiratory burst cũng giảm.

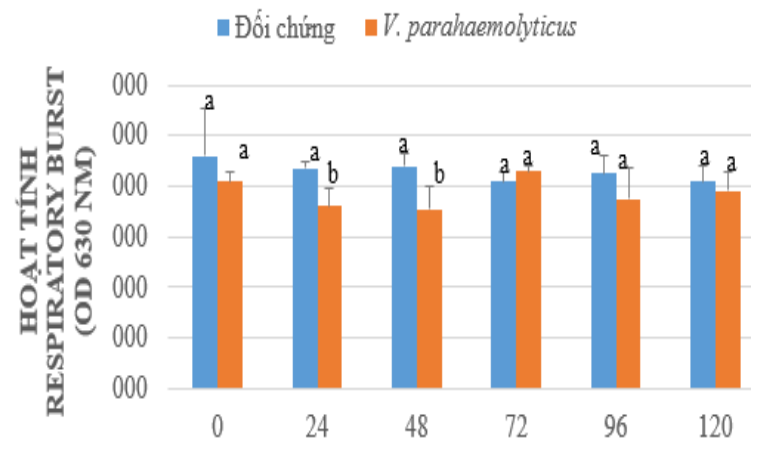

THỜI ĐIẺM THU MÃU (GIỜ)

Hình 4. Sự thay đổi hoạt tính respiratory burst sau khi tôm bị cảm nhiễm bởi vi khuẩn $V$. parahaemolyticus

\section{Kết Luận}

Tổng tế bào máu, hoạt tính phenoloxidase và hoạt tính respiratory burst của tôm ở nhóm gây nhiễm bởi vi khuẩn Vibrio parahaemolyticus được ghi nhận ở thời điểm 24 và 48 giờ có khuynh hướng giảm và khác biệt có ý nghĩa thống kê so với nhóm đối chứng. Ở những thời điểm thu mẫu tiếp theo $(72,96$ và 120 giờ $)$ thì không có sự khác biệt giữa hai nghiệm thức. Như vậy, khả năng đáp ứng miễn dịch tự nhiên của tôm thẻ Penaeus vannamei bị suy yếu sau khi tôm bị vi khuẩn Vibrio parahaemolyticus tấn công.

\section{Tài Liệu Tham Khảo (References)}

Bachere, E., Gueguen, Y., Gonzalez, M., De Lorgeril, J., Garnier, J., \& Romestand, B. (2004). Insights into the anti-microbial defense of marine invertebrates: the penaeid shrimps and the oyster Crassostrea gigas. Immunological Reviews 198, 149-168.

Dang, O. T. H., Le, T. H., \& Nguyen, P. T. (2012). Optimization and application of protocols for immune response analysis in Macrobrachium rosenbergii. Can Tho University Journal of Science 21b, 10-18.

Dantas-Lima, J. J., Vo, T. V., Corteel, M., Grauwet, K., An, N. T. T., Sorgeloos, P., \& Nauwynck, H. J. (2013). Separation of Penaeus vannamei haemocyte subpopulations by iodixanol density gradient centrifugation. Aquaculture 408-409, 128-135.

Hansen (2000). Use of a hemacytometer. Laboratory procedures, Department of Animal Sciences, University of Florida, Florida, USA.

Hernández-López, J., Gollas-Galván, T., \& VargasAlbores, F. (1996). Activation of the prophenoloxidase system of the brown shrimp (Penaeus californiensis, Holmes). Comparative Biochemical Physiology 113C (1), 61-66.

Hrubec, C. T., Cardinale, J. L., \& Smith, S. A. (2000). Hematology and plasma chemistry reference intervals for cultured tilapia (Oreochromis hydrid). Veterinary Clinical Pathology 29(1), 7-12.

Hsieh, S. L., Ruan, Y. H., Li, Y. C., Hsieh, P. S., Hu, C. H., \& Kuo, C. M. (2008). Immune and physiological responses in Pacific white shrimp (Penaeus vannamei) to Vibrio alginolyticus. Aquaculture 275(1-4), 335-341.

Hsu, S. W., \& Chen, J. C. (2007). The immune response of white shrimp Penaeus vannamei and its susceptibility to Vibrio alginolyticus under sulfide stress. Aquaculture 271(1-4), 61-69.

Johansson, M. W., Keyser, P., Sritunyalucksana, K., \& Söderhäll, K. (2000). Crustacean haemocytes and haematopoiesis. Aquaculture 191(1-3), 45-52.

Jose, S., Mohandas, A., Philip, R., \& Bright Singh, I. S. (2010). Primary hemocyte culture of Penaeus monodon as an in vitro model for white spot syndrome 
virus titration, viral and immune related gene expression and cytotoxicity assays. Journal of Invertebrate Pathology 105(3), 312-321.

Le Moullac, G., \& Haffner, P. (2000). Environmental factors affecting immune responses in Crustacea. Aquaculture 191(1-3), 121-131.

Lee, C. T., Chen, I. T., Yang, Y. T., Ko, T. P., Huang, Y. T., Huang, J. Y., Huang, M. F., Lin, S. J., Chen, C. Y., Lin, S. S., Lightner, D. V., Wang, H. C., Wang, A. H., Wang, H. C., Hor, L. I., \& Lo, C. F. (2015). The opportunistic marine pathogen Vibrio parahaemolyticus becomes virulent by acquiring a plasmid that expresses a deadly toxin. Proceedings of National Academy of Sciences U.S.A 112(34), 10798-10803.

Lightner, D. (2011). Virus diseases of farmed shrimp in the Western Hemisphere (the Americas): A review. Journal of Invertebrate Pathology 106(1), 110-130.

Liu, C. H., Yeh, S. T., Cheng, S. Y., \& Chen, J. C. (2004). The immune response of white shrimp Litopenaeus vannamei and its susceptibility to Vibrio infection in relation with the moult cycle. Fish \& Shellfish Immunology 16(2), 151-161.

Lopez-Leon, P., Luna-Gonzalez, A., Escamilla-Montes, R., Flores-Miranda, M. C., Fierro-Coronado, J. A., Alvarez-Ruiz, P., \& Diarte-Plata, G. (2016). Isolation and characterization of infectious Vibrio parahaemolyticus, the causative agent of AHPND, from the whiteleg shrimp (Litopenaeus vannamei). Latin American Journal of Aquatic Research 44(3), 470-479.

Matozzo, V., \& Marin, M. G. (2010). The role of haemocytes from the crab Carcinus aestuarii (Crustacea, Decapoda) in immune responses: A first survey. Fish \& Shellfish Immunology 28(4), 534-541.

Menz, A., \& Blake, B. F. (1980). Experiments on the growth of Penaeus vannamei Boone. Journal of Experimental Marine Biology and Ecology 48(2), 99-111.

Perazzolo, L. M., \& Barracco, M. A. (1997). The prophenoloxidase activating system of the shrimp Penaeus paulensis and associated factors. Developmental Comparative Immunology 21, 385-395.

Reed, L. J., \& Muench, H. (1938). A simple method of estimating fifty per cent endpoints. American Journal of Hygiene 27(3), 493-497.

Robertson, P. A. W., Calderon, J., Carrera, L., Stark, J. R., Zherdmant, M., \& Austin, B. (1998). Experimental Vibrio harveyi infections in Penaeus vannamei larvae. Diseases of Aquatic Organism 32(2), 151-155.

Söderhäll, K., \& Smith, V. J. (1983). Separation of the haemocyte populations of Carcinus maenas and other marine decapods, and prophenoloxidase distribution. Developmental \& Comparative Immunology 7(2), 229-239.
Song Y. L., \& Hsieh Y. T. (1994). Immunostimulation of tiger shrimp (Penaeus monodon) hemocytes for generation of micribicidal substances: Analysis of reactive oxygen species. Developmental and Comparative Immunology 18(3), 201-209.

Song, Y. L., Yu, C. I., Lien, T. W., Huang, C. C., \& Lin, M. N. (2003). Haemolymph parameters of Pacific white shrimp (Litopenaeus vannamei) infected with Taura syndrome virus. Fish \& Shellfish Immunology 14(4), 317-331.

Sritunyalucksana, K., \& Söderhäll, K. (2000). The proPO and clotting system in crustaceans. Aquaculture 191, 53-69.

Thakur, A. B., Vaidya, R. B., \& Suryawanshi S. A. (2003). Pathogenicity and antibiotic susceptibility of Vibrio species isolated from moribund shrimps. Indian Journal of Marine Sciences 32(1), 71-75.

Tran, L. H., Nunan, L., Redman, R.M., Mohney, L. L., Pantoja, C. R., Fitzsimmons, K., \& Lightner, D. V. (2013). Determination of the infectious nature of the agent of acute hepatopancreatic necrosis syndrome affecting penaeid shrimp. Diseases of Aquatic Organism 105(1), 45-55.

Tseng, I. T., \& Chen, J. C. (2004). The immune response of white shrimp Litopenaeus vannamei and its susceptibility to Vibrio alginolyticus under nitrite stress. Fish \& Shellfish Immunology 17(4), 325-333.

Van de Braak, C., Faber, R., \& Boon, J. H. (1996). Cellular and humoral characteristics of Penaeus monodon (Fabricius, 1798) haemolymph. Comparative Haematology International 6(4), 194-203.

Vo, T. V., Dantas-Lima, J. J., Khuong, T. V., Li, W., Grauwet, K., Bossier, P., \& Nauwynck, H. J. (2015). Differences in uptake and killing of pathogenic and non-pathogenic bacteria by haemocyte subpopulations of penaeid shrimp, Litopenaeus vannamei, (Boone). Journal of Fish Diseases 39(2), 163-174.

Wang, L. U., \& Chen, J. C. (2005). The immune response of white shrimp Litopenaeus vannamei and its susceptibility to Vibrio alginolyticus at different salinity levels. Fish \& Shellfish Immunology 18(4), 269-278.

Zorriehzahra, M., \& Banaederakhshan, R. (2015). Early mortality syndrome (EMS) as new emerging threat in shrimp industry. Advances in Animal Veterinary Sciences $3(2 \mathrm{~s}), 64-72$. 